\title{
Araştırma-Geliş̧irme Harcamaları ve Ekonomik Büyüme İlişkisi: Yükselen Piyasalar Ekonomileri İçin Bir Uygulama
}

\section{Research-Development Expenditures and Economic Growth Relationship: An Applicatıon for Economies Rise Markets}

\author{
Ferhat İspiroğlu ${ }^{a}$, Meltem Kılıç b* \\ ${ }^{a}$ Dr. Öğr. Üyesi, Giresun Üniversitesi, Görele Uygulamalı Bilimler Yüksek Okulu, Lojistik Yönetimi Bölümü, 28800, Giresun/Türkiye \\ ORCID: 0000-0003-4374-5988 \\ ${ }^{\mathrm{b}}$ Dr. \\ ORCID: 0000-0001-8978-9076
}

\section{MAKALE BİLGİSİ \\ Makale Geçmişi: \\ Başvuru tarihi: 02 Haziran 2018 \\ Düzeltme tarihi: 10 Eylül 2018 \\ Kabul tarihi: 14 Kasım 2018}

\section{Anahtar Kelimeler:}

Ar-Ge

Ekonomik Büyüme

Panel Veri Analizi
ÖZ

Bilim ve teknolojik alanlarında ortaya çıkan yenilikler ekonomik gelişme ve büyümenin itici güçlerinden biridir. Ar-Ge faaliyetlerine yapılan yatırımlar ekonomik büyümenin yanında rekabet düzeyinin de artmasında etkilidir. İçsel büyüme modellerinde de Ar-Ge'nin ekonomik büyüme üzerinde olan etkisine dikkat çekilmektedir. Sürdürülebilir bir ekonomik büyümenin gerçekleştirilebilmesinde sürekli yenilik anlayışının benimsenmesi önemlidir. Yenilikçi üretim sistemlerinin geliştirilmesi verimlilik, ekonomik büyüme ve refah artışının sağlanmasında anahtar görevi üstlenmektedir. Bu kapsamda, çalışmada IMF'nin yükselen piyasa ekonomisi olarak nitelendirdiği 15 ülkede Ar-Ge ve ekonomik büyüme arasındaki ilişki 1996-2015 yılları arası için panel veri analizi kullanılarak test edilmiştir. Analiz sonucunda, 15 yükselen piyasa ekonomisinde Ar-Ge'ye yapılan harcamalarla ekonomik büyüme arasında pozitif yönlü bir ilişki bulunmuş, ayrıca iki değişken arasında karşılıklı olarak çift yönlü nedensellik olduğu bilgisine ulaşılmıştır.

\section{A B S T R AC T}

Innovations in science and technology are one of the driving forces of economic development and growth. Investments in R \& D activities are effective in increasing the level of competition as well as economic growth. It also draws attention to the impact of $\mathrm{R} \& \mathrm{D}$ on economic growth in internal growth models. It is important to adopt a continuous understanding of innovation in achieving sustainable economic growth. The development of innovative production systems is key to ensuring efficiency, economic growth and prosperity. In this context, the relationship between R \& D and economic growth in the 15 countries that the IMF described as the rising market economy of the IMF was tested by using panel data analysis between 1996-2015. As a result of the analysis, a positive relationship was found between the expenditures made on R \& D and economic growth in 15 emerging market economies, and it was also learned that there was a mutual bi-directional causality between the two variables.

\section{Giriş}

Ar-Ge, "insan, toplum bilgisi ve kültür gibi alanlarda bilgi birikiminin arttırılmass ve yeni uygulamaların tasarlanmasında bu birikimlerin kullanılması amacıyla sistematik olarak üstlenilen yenilikçi çalışmaların ortaya konulması" olarak tanımlanmaktadır (OECD, 1993: 13).

Yeni ürün, yeni üretim sistemleri ve bilgi ile sonuçlanan araştırma ve geliştirme çalışmalarını teknik değişiminin ana kaynağ 1 olarak nitelendirmek mümkündür. Ar-Ge'nin üretkenlik üzerindeki etkisi farklı kanallar üzerinden kendisini gösterebilmektedir. Modern teknoloji, endüstriyel ekonomiler, yaparak ya da tasarlayarak öğrenme gibi faaliyetler genellikle Ar-Ge çalışmaları sonucunda ortaya çıkan teknolojilerin temelini oluşturmaktadır. Ar-Ge sayesinde yeni ürün ve hizmetlerde, daha yüksek kalite ile yeni üretim süreçleri ortaya çıkmaktadır. Bu sayede gerek firma düzeyinde gerekse makroekonomik düzeyde verimlilik artışı sağlanmış olmaktadır (Dominique ve Potterie, 2001: 105).

\footnotetext{
* Sorumlu yazar/Corresponding author.

e-posta: meltem.kilic@hotmail.com
} 
Yurtiçinde yapılan Ar-Ge yatırımlarına olduğu kadar yabancı menşeli Ar-Ge yatırımları bir ülkedeki verimlilik artış1 üzerinde etkili olabilmektedir (Coe ve Helpman, 1995). Yabancı menșeli bir bilgi diğer yabancı ulusal ekonomiler için üçüncü bir teknoloji kaynağı durumundadır. Küreselleşmenin etkisiyle teknolojinin sınırları aşması daha kolay hale gelmiştir. Patent, lisans alımı veya know-how gibi faktörlerle bilgi küresel çapta yayılım gösterebilmektedir. Bununla birlikte bu bilginin bir ülkenin üretkenliği üzerindeki etkisi, alıcı ülkenin bu bilgiyi etkin şekilde kullanma kapasitesine bağlıdır. Bu yüzden ülkenin belirli bir teknolojik aktivite kabiliyetine sahip olması gerekebilmektedir. Genel olarak bu durum ekonominin "emilim kapasitesi" olarak isimlendirilmektedir (Omoregie, 2015: 2).

Ar-Ge kapsamında yapılan yatırımlar bir ülkenin hem rekabet gücünün hem de ekonomik gelişmişliğinin değerlendirilmesinde büyük bir öneme sahiptir. Ar-Ge ile sermaye birikimi, beşeri sermaye gelişimi ve üretim alanlarında yenilik gibi birçok kanaldan ekonomik büyüme desteklenmektedir (Bor vd., 2010: 171). Geleneksel olarak Ar-Ge yatırımları teknolojik potansiyeli, buna bağlı olarak inovasyonu ve ekonomik büyümeyi güvence altına alan temel stratejilerden biri olarak kabul edilmektedir (Trajtenberg, 1990).

Ar-Ge harcamaları firmalara yeni ve üstün ürünler veya süreçler sunmalarını konusunda daha yüksek teknoloji standardı elde etmelerini sağlamakta bu ise daha yüksek gelir ve büyüme seviyelerinin gerçekleşmesine yol açmaktadır. Romer (1990) ve Lichtenberg'de (1992) teknoloji yatırımı (Ar-Ge harcamaları) neticesinde artan verimlilik artışı (ekonomik büyüme) arasındaki ilişkiye dikkat çekmektedirler (Osorio ve Pose, 2004: 435).

Ekonomik büyüme sürecinin anlaşılmasında önemli konuma sahip olmakla birlikte eksiklikleri bulunan neoklasik büyüme modeli daha sonra yerini içsel büyüme modellerine bırakmıştır. Ölçeğe göre artan getiri ve teknolojinin içsel olduğu yaklaşımı üzerinde duran içsel büyüme modelleri neoklasik modelin eksiklerini gidermek amacıyla ortaya konulmuştur. Ar-Ge ve beşeri sermaye açısından teknolojik girdiyi içsel olarak kabul eden ve Romer, Lucas, Barro, Grossman ve Helpman ile Aighon Howitt gibi iktisat düşünürleri tarafından geliştirilen modeller literatürdeki yerlerini almışlardır. Modellere göre ekonominin uzun dönemde büyüme göstermesi üretim sektörlerine aktarılan araştırmacı (bilim adamı, teknik eleman, mühendis vb.) sayısına bağlıdır. Sahip olunan bu girdilerin düzeyi ve kaynakların başarıyla Ar-Ge sektörüne aktarım başarısı ölçüsünde ekonomik büyüme oranı gerçekleşmektedir (Genç ve Atasoy, 2010: 28).

Yapılan birçok çalışmada Ar-Ge faaliyetlerine yapılan yatırımların artan getirilere neden olduğuna dikkat çekilmektedir. Bu bağlamda Ar-Ge'ye yapılan yatırımların geri dönüşünün yatırım hacmiyle olumlu yönde ve kümülatif etkilerden olumlu yararlanma eğiliminde olduğu dile getirilmektedir (Dosi, 1998: 1132). Benzer şekilde, Audretsch ve Feldman (1996)'de Ar-Ge faaliyetlerinin ve bilgi yayılımlarının daha yüksek ekonomik büyümenin yaşanmasına neden olduğuna dikkat çekmektedir (Audretsch ve Feldman (1996: 632).
Yükselen piyasa ekonomileri göstermiș oldukları yenilikçi uygulamalar ve gösterdiği yüksek ekonomik performans ile ön plana çıkmaktadır. Gerçekleştirdikleri yüksek sürdürülebilir büyüme hızlarıyla gelişmekte olan ülkelerden ayrilmaktadırlar (Melemen, 2007: 8-9).

Ülkeler arasında bireysel farklılıkların bulunmasıyla birlikte yükselen piyasa ekonomilerinde benzer olan özellik sahip oldukları büyüme potansiyelleri olarak ortaya çıkmaktadır. Ekonomiyi uyarıcı formlardan biri olan yeni teknolojilerin kullanımı ve ülkeye çekilmesi yükselen piyasa ekonomileri gibi iletken politikalara sahip ülkelerde daha rahat gerçekleşebilmektedir (Miller, 1998: 17-18).

Yükselen piyasa ekonomileri daha üretken kapasiteye sahip alanlara yatırım yapmakta, geleneksel ekonomi anlayışından uzaklaşarak serbest piyasa ya da karma ekonomi sistemini benimseyerek hızlı sanayileşme yolunda ilerlemektedirler.

Hızlı bir ekonomik büyümenin sağlanması için yükselen piyasa ekonomisi ülkelerin çoğu ihracat odaklı bir büyüme stratejisi izlemektedir. Ayrıca bu ülkelerin çoğunda global piyasalara kıyasla sosyo-ekonomik özellikleri gereği daha düşük maliyetli emtia üretimi yapabilmektedirler. $\mathrm{Bu}$ ise yabancı yatırımcıları yükselen piyasa ekonomisi ülkelere çeken en önemli niteliklerin başında gelmektedir.

Küresel dünya ekonomisinin büyümesinde bir motor görevi üstlendiği dile getirilen yükselen piyasa ekonomilerinde ArGe yatırımları da bu genel çerçevede büyük önem taşımaktadır. Ar-Ge faaliyetlerine yapılan yatırımlar yükselen piyasa ekonomilerinin dünya ekonomisindeki artan rolüne bağlı olarak daha çok ön plana çıkmaktadır.

Yükselen piyasa ekonomisi olarak nitelendirilen ülkeler konusunda tam bir fikir birliği bulunmamakla birlikte bu ülkeleri sınıflandıran faklı kurum ve kuruluşlar bulunmaktadır. $\mathrm{Bu}$ siniflandırmaları yapan kurum ve kuruluşların başında, EMGP (Emerging Market Global Players), FTSE (Financial Times Stock Exchange), DowJones, MSCI (Modern Index Strategy Indexes) ve IMF (International Monetary Fund) gelmektedir.

2017 tarihli IMF raporunda; Arjantin, Brezilya, Çin, Endonezya, Filipinler, G. Afrika, Hindistan, Kolombiya, Letonya, Macaristan, Malezya, Meksika, Polonya, Rusya, Tayland, Türkiye ve Ukrayna olmak üzere toplam 17 ülke yükselen piyasa ekonomisi olarak sinıflandırılmaktadır (IMF, 2017: 2).

Bu kapsamda çalışmada IMF'in yükselen piyasa ekonomisi olarak sınıflandırdığı ve verilerine ulaşılabilen 15 ülkenin Ar-Ge çalışmaları için yaptıkları harcamaların ülkelerin ekonomik büyümeleri üzerindeki etkisi panel veri yöntemiyle analiz edilmiştir. Yükselen piyasa ekonomisindeki ülkelerin tercih edilme nedeni daha önce bu ülke grubunun ar-ge harcamaları ile büyüme ilişkisinin araştırıldığ 1 bir çalıșmaya rastlanılmamasıdır. Çalıșmada öncelikle farklı ülke gruplarının ve ülkelerin ar-ge harcamalarıyla ekonomik büyüme arasındaki ilişkiyi araştıran çalışmaları içeren literatür taramasına yer verilmiștir. Daha sonra analizde kullanılacak veri seti ve model açıklanmıştır. Yöntem ve bulgular kısmında çalışmada kullanılan panel veri yöntemleri ve analiz sonuçlarına yer verilmiştir. Sonuç ve değerlendirme kısmında ise genel bir değerlendirme yapılmıştır. 


\section{Literatür Taraması}

Ar-Ge harcamaları ve ekonomik büyüme ilişkisinin araştırıldığı ampirik çalışmalar incelendiğinde ilişkinin yönü ile ilgili analizi yapılan ülkenin gelişmişlik düzeyine ve kullanılan değișkenlere göre farklılık göstermekte ve ilişkinin yönü hakkında kesin bir görüş olmadığı görülmektedir. Bu çalışmalar Tablo 1'de özetlenmiştir.

Tablo 1. Ar-Ge Harcamaları ve Ekonomik Büyüme Literatür Özeti

\begin{tabular}{|c|c|c|c|}
\hline Yazar & Dönem ve Veri Seti & Kullanılan Ekonometrik Yöntem & Sonuç \\
\hline Lichtenberg (1992) & $\begin{array}{c}74 \text { Ülke } \\
\text { Özel ve Kamu Sektörü } \\
(1964-1989)\end{array}$ & Panel Veri Analizi & $\begin{array}{l}\text { Özel Sektör Ar-Ge Harcamalarının Büyümeyi } \\
\text { Pozitif Etkilemektedir. Kamu Sektörünün Yaptığı } \\
\text { Ar-Ge Harcamaları ile Büyüme Arasında İlişki } \\
\text { Bulunamamıştır. }\end{array}$ \\
\hline Goel vd. (2008) & $\begin{array}{c}\text { ABD } \\
(1953-2000)\end{array}$ & ARDL & $\begin{array}{l}\text { ABD’nin Ekonomik Büyümesi ile Ar-Ge } \\
\text { yatırımları arasında pozitif bir ilişkinin olduğunu } \\
\text { bulgulamışlardır. }\end{array}$ \\
\hline Serén (1999) & $\begin{array}{l}\text { OECD ülkeleri } \\
(1965-1990)\end{array}$ & Doğrusal Olmayan EKK & $\begin{array}{l}\text { Ar-Ge ve ekonomik büyüme arasında güçlü bir } \\
\text { ilişki tespit etmiştir. }\end{array}$ \\
\hline Ülkü (2004) & $\begin{array}{l}\text { OECD'de yer alan } 20 \text { ülke ve } \\
\text { OECD üyesi olmayan } 10 \text { ülke } \\
\text { (1981-1997) }\end{array}$ & $\begin{array}{l}\text { Sabit Etki Modeli (Fix-Effect) ve } \\
\text { GMM }\end{array}$ & $\begin{array}{l}\text { Büyüme ve Ar-Ge harcamaları arasında ilişki her } \\
\text { iki ülke grubunda da güçlü olduğuna ulaşmıştır. }\end{array}$ \\
\hline $\begin{array}{c}\text { Yanyun ve } \\
\text { Mingqian (2004) }\end{array}$ & $\begin{array}{l}8 \text { Asya Ülkesi } \\
(1994-2003)\end{array}$ & Panel Regresyon ve GMM & $\begin{array}{l}\text { Ekonomik Büyüme ve Ar-Ge arasında pozitif bir } \\
\text { ilişkinin olduğunu tespit edilmiştir. }\end{array}$ \\
\hline Yu-ming vd. (2007) & $\begin{array}{c}\text { Çin } \\
(1953-2004)\end{array}$ & $\begin{array}{l}\text { Eşbütünleşme ve Granger } \\
\text { Nedensellik Testi }\end{array}$ & $\begin{array}{l}\text { Ar-Ge ve ekonomik büyüme değişkenlerinin } \\
\text { birbirini etkilediğine ve aralarında nedensellik } \\
\text { iliş̧kisinin olduğuna ulaşmışlardır. }\end{array}$ \\
\hline $\begin{array}{l}\text { Gülmez ve } \\
\text { Yardımcıoğlu, } \\
(2012) \\
\end{array}$ & 21 OECD (1990-2010) & $\begin{array}{c}\text { Panel Eşbütünleşme, Pedroni } \\
\text { DOLS ve FMOLS, Pedroni Panel } \\
\text { Nedensellik } \\
\end{array}$ & $\begin{array}{l}\text { Ar-Ge ve ekonomik büyüme arasında çift yönlü bir } \\
\text { ilişki tespit edilmiştir }\end{array}$ \\
\hline $\begin{array}{l}\text { Amimi ve Alerasoul } \\
\text { (2009), }\end{array}$ & $\begin{array}{c}\text { Türkiye'ninde İçinde } \\
\text { Bulunduğu } 30 \text { Gelişmekte } \\
\text { Olan Ülke (2000-2006) } \\
\end{array}$ & $\begin{array}{l}\text { Rassal Etki Modeli } \\
\text { (Random Effect) }\end{array}$ & $\begin{array}{l}\text { Ar-Ge'ye yapılan yatırımların ekonomik büyümeyi } \\
\text { pozitif yönde etkilediği tespit edilmiştir. }\end{array}$ \\
\hline $\begin{array}{l}\text { Genç ve Atasoy } \\
(2010)\end{array}$ & 34 ülke (1997-2008) & Panel Nedensellik Testi & $\begin{array}{l}\text { Ar-Ge'den büyümeye doğru tek yönlü bir } \\
\text { nedensellik ilişkisinin varlığına ulaşmışlardır. }\end{array}$ \\
\hline $\begin{array}{l}\text { Akıncı ve Sevinç } \\
\text { (2013) }\end{array}$ & Türkiye (1990-2011) & $\begin{array}{l}\text { Johansen Eşbütünleşme Testi, } \\
\text { Granger Nedensellik Testi, }\end{array}$ & $\begin{array}{l}\text { Kamusal Ar-Ge harcamaları dişındaki diğer Ar- } \\
\text { Ge'nin ekonomik büyüme üzerinde olumlu bir } \\
\text { etkisi olduğu sonucuna ulaşılmıştır. }\end{array}$ \\
\hline $\begin{array}{l}\text { Sadraoui, Ali ve } \\
\text { Dequachi (2014) }\end{array}$ & $\begin{array}{l}32 \text { Endüstriyel ve Gelişmekte } \\
\text { Olan Ülke (1970-2012) }\end{array}$ & Panel Nedensellik Testi & $\begin{array}{l}\text { Ekonomik büyümeden Ar-Ge iş birliğine doğru tek } \\
\text { yönlü nedensellik ilişkisinin olduğu tespit } \\
\text { edilmiştir. }\end{array}$ \\
\hline $\begin{array}{c}\text { Altıntaş ve Mercan } \\
(2015)\end{array}$ & 21 OECD (1996-2011) & $\begin{array}{l}\text { Durbin-H Panel Eşbütünleşme } \\
\text { Testi ve Eşbütünleşme Tahmincisi }\end{array}$ & $\begin{array}{l}\text { Ar-Ge harcamalarının büyüme üzerinde bir } \\
\text { etkisinin olduğunu bulgulamışlardır. }\end{array}$ \\
\hline $\begin{array}{l}\text { Gümüş ve Celikay } \\
\text { (2015) }\end{array}$ & $\begin{array}{l}32 \text { Gelişmiş, } 20 \text { Gelişmekte } \\
\text { Olan Ülke (1996-2010) }\end{array}$ & Panel Eşbütünleşme Testi & $\begin{array}{l}\text { Gelişmiş ve gelişmekte olan ülkelerde ar-ge } \\
\text { harcamalarının ekonomik büyüme üzerinde uzun } \\
\text { dönemde pozitif bir etkisi olduğu tespit edilmiştir. }\end{array}$ \\
\hline $\begin{array}{l}\text { Sağlam vd. } \\
\text { (2017) }\end{array}$ & 26 Ülke (1996-2004) & $\begin{array}{l}\text { Panel Eşbütünleşme Panel } \\
\text { Nedensellik }\end{array}$ & $\begin{array}{l}\text { Ar-Ge'den ekonomik büyümeye doğru tek yönlü } \\
\text { İlişki Bulunmuştur. }\end{array}$ \\
\hline $\begin{array}{c}\text { Korkmaz } \\
(2010)\end{array}$ & Türkiye (1990-2008) & $\begin{array}{c}\text { Johansen Eşbütünleşme Granger } \\
\text { Nedensellik }\end{array}$ & $\begin{array}{l}\text { Ar-Ge harcamalarından ekonomik büyümeye doğru } \\
\text { tek yönü ilişkinin olduğu bulgusuna ulaşılmıştır. }\end{array}$ \\
\hline $\begin{array}{l}\text { Altın ve Kaya } \\
\text { (2009) }\end{array}$ & $\begin{array}{l}\text { Türkiye } \\
(1990-2005)\end{array}$ & $\begin{array}{l}\text { Johansen Eşbütünleşme Testi, } \\
\text { Granger Nedensellik Testi }\end{array}$ & $\begin{array}{l}\text { Ar-Ge harcamaları büyümeyi artırmaktadır. Kısa } \\
\text { dönemde ise Ar-ge ve büyüme arasından bir ilişkiye } \\
\text { ulaşılmamıştır. }\end{array}$ \\
\hline $\begin{array}{l}\text { Bozkurt } \\
(2015)\end{array}$ & $\begin{array}{c}\text { Türkiye } \\
(1998-2013)\end{array}$ & $\begin{array}{c}\text { Johansen Eşbütünleşme, Granger } \\
\text { Nedensellik }\end{array}$ & $\begin{array}{l}\text { Ekonomik Büyümeden Ar-Ge’ye Doğru Tek Yönlü } \\
\text { Nedensellik Tespit Edilmiştir. }\end{array}$ \\
\hline
\end{tabular}

Tablodaki sonuçlara genel olarak baktığımızda, ülkenin gelişmişlik düzeyine ve analizin yapıldığı döneme bağlı olarak Ar-Ge harcamaları ve ekonomik büyüme arasındaki etkileşimin değiştiğine ulaşılmıştır. Bu nedenle, Ar-Ge kapsamında yapılan harcamaların mı ekonomik büyümeyi, ekonomik büyümenin mi Ar-Ge harcamalarını etkilediği konusunda kesin bir yargıya varmak mümkün değildir.
Tablo 2. Analizde kullanılan Değişkenler

\begin{tabular}{ccc}
\hline Değişkenler & Açıklama & Veri Yıl Aralı̆̆ ve Kaynak \\
\hline \multirow{2}{*}{ AR-GE } & $\begin{array}{c}\text { Ar-Ge Harcamaları } \\
(\% \text { GSYİH) }\end{array}$ & $\begin{array}{c}\text { Dünya Bankası, WDI, 1996- } \\
\text { (\% } 2015\end{array}$ \\
\hline \multirow{2}{*}{ GSYİH } & Gayrisafi Yurt İçi & Dünya Bankası, WDI, 1996- \\
& Hasıla & 2015 \\
& (\% Büyüme Oran1) & \\
\hline
\end{tabular}

\section{Veri Seti ve Model}

Çalışmada kullanılan değişken ve verilere ait bilgiler Tablo 2'de, ülkelere ise Tablo 3'de yer verilmektedir. 
Tablo 3. Analizde kullanılan Ülkeler

\begin{tabular}{|c|c|c|c|}
\hline Sira & Ülkeler & Sira & Ülkeler \\
\hline 1. & Arjantin & 9. & Malezya \\
\hline 2. & Brezilya & 10. & Meksika \\
\hline 3. & Çin & 11. & Polonya \\
\hline 4. & Güney Afrika & 12. & Rusya \\
\hline 5. & Hindistan & 13. & Tayland \\
\hline 6. & Kolombiya & 14. & Türkiye \\
\hline 7. & Letonya & 15. & Ukrayna \\
\hline 8. & Macaristan & & \\
\hline
\end{tabular}

Bu çalışmadaki öncül beklenti Ar-Ge harcamaları arttığında ekonomik büyümenin artacağı ve ekonomik büyüme arttığında Ar-Ge harcamalarının artacağı yönündedir. Bu bağlamda; Gülmez ve Yardımcıŏ̆lu (2012) ve Sağlam vd. (2017) çalışmaları incelenerek aşağıdaki model tahmin edilmiştir.

\section{Model: GSYİH=f(AR-GE)}

Çalışmada kullanılan veriler ile yapılacak olan panel veri analizi için E-views 8.0 ve Gauss Light 13x86 paket programları kullanılmıştır. Panel veri analizi, zaman serisi ve yatay kesitlerin bir araya getirilerek oluşturduğu modellerdir (Baltagi, 2014: 1).

Panel veri analizinde, zaman kesiti ve yatay kesiti boyutu arasındaki ilişkiyi inceleyebilmek amacıyla kullanılan basit regresyon modeli aşağıda şekilde kurulmaktadır (Baltagi, 2014:13):

$Y_{i t}=\beta_{0}+X_{k i t} \beta+u_{i t}$

Modelde, i yatay kesit boyutunu, $\mathrm{t}$ ise zamanı, $\beta_{0}$ sabiti ifade etmektedir.

\section{Yöntem ve Bulgular}

Çalışmada kullanılan ülkelere ait verilen için yapılan panel veri analizinde serilerin homojen olması ve seriler arasında yatay kesit bağımlılı̆̆ının olması kullanılan yöntemin belirlenmesinde önemli bir ölçüdür. Bu testler ön test olarak ifade edilmektedir. Çünkü, serilerin homojen veya heterojen olması ve yatay kesit bağımlığının olup olmaması birim kök testleri ve eş bütünleşme testlerinin seçiminde yol göstericidir. İlk olarak çalışmada kullanılacak serilerin homojenliği Delta testi ile incelenmektedir.

Delta testi iki ayrı şekilde hesaplanmaktadır. Bu testler için kurulan denklemler ise aşağıdaki gibidir (Pesaran ve Yamagata, 2008: 56).

$\tilde{\Delta}=\sqrt{N} \frac{N^{-1} \check{S}-k}{\sqrt{2 k}}$

$\tilde{\Delta}$, test istatistiğinin düzeltilmiş değeri $\tilde{\Delta}_{a d j}$ ifade edilmekte ve aşağıdaki gibi hesaplanmaktadır:

$\tilde{\Delta}_{a d j}=\sqrt{N} \frac{N^{-1} \check{S}-E\left(\tilde{Z}_{i t}\right)}{\sqrt{\operatorname{Var}\left(\left(\tilde{Z}_{i t}\right)\right.}}$

$\tilde{\Delta}$ ve $\tilde{\Delta}_{a d j}$ Delta test istatistikleri ile kurulan hipotezler aşağıdaki gibi ifade edilmektedir:

$H_{0}: \beta_{1}=\beta_{2}=\cdots=\beta_{n}=\beta$ (Tüm $\beta_{i}^{\prime}$ leriçin $)$

$H_{1}: \beta_{1}=\beta_{2}=\cdots \neq \beta_{n}($ En az bir i için $)$

Homojenitenin belirlenmesi için yapılan Delta testi sonuçları Tablo 4'da açıklanmıștır.
Tablo 4. Delta Homojenlik Test Sonuçları

\begin{tabular}{|c|c|c|}
\hline Test & İstatistik Değerleri & Prob. Değerleri \\
\hline$\tilde{\Delta}$ & -1.350 & 0.912 \\
\hline$\tilde{\Delta}_{a d j}$ & -1.458 & 0.928 \\
\hline
\end{tabular}

Delta testi sonuçlarına göre, modelde yer alan değişkenler homojendir. Olasılık değerleri \%5'den fazla olduğu için sıfır hipotezi kabul edilmiştir.

Delta testine göre serilerin homojen olduğuna karar verdikten sonra yapılan yatay kesit bağımlılı̆̆ testi ile analizde kullanılacak değişkenler için panelde bulunan ülkelerde meydana gelen şokların birbirini etkileyip etkilemediğini ortaya koymaktadır.

Yatay kesit bağımlılı̆̆ testleri dört tanedir. Bu testlerden ilki Breusch ve Pagan (1980) geliştirdiği Lagrange çarpanı LM testidir. LM testi eşitliği modeldeki gibidir:

$L M=T \sum_{i=1}^{N-1} \sum_{j=i+1}^{N} \hat{\rho}_{i j}^{2}$

Yukarıdaki eşitlikteki $\hat{\rho}$, kalıntıların ikili korelasyonunu göstermektedir. Bu test için kurulan sıfır hipotezi yatay kesitler arasında ilişkinin olmadığı şeklindedir. Ayrıca, zaman boyutunu ifade eden $\mathrm{T}$ sonsuza giderken yatay kesit boyutu $(\mathrm{N})$ sabit ise $\frac{N(N-1)}{2}$ serbestlik derecesinde ki-kare olarak asimptotik dağılım göstermekte ve $\mathrm{T}>\mathrm{N}$ olduğu durumlarda kullanıldığ 1 varsayılmaktadır (Pesaran, 2004:4).

İkinci yatay kesit bağımlılığı testi, Pesaran (2004) $C D_{L M}$ testidir. $C D_{L M}$ testi, hem zaman boyutunun hem de yatay kesit boyutunun büyük olduğu durumlarda kullanılmaktadır (Pesaran, 2004:5, Güloğlu ve İvrendi, 2010:384). Testin modeli şu şekildedir:

$C D_{L M}=\sqrt{\frac{1}{N(N-1)}} \sum_{i=j}^{N-1} \sum_{j=i+1}^{N}\left(T \hat{\rho}_{i j}^{2}-1\right) \sim N(0,1)$

Kurulan modelin sifir hipotezi, "Yatay kesit ve zamanın sonsuz olduğu durumlarda yatay kesit bağımlılığı yoktur." şeklindedir.

Üçüncü test Pesaran (2004) tarafından geliştirilen CD testtir. $\mathrm{CD}$ testi ise $\mathrm{N}>\mathrm{T}$ olduğu durumlarda kullanılmaktadır. $\mathrm{Bu}$ test için geliştirilen model aşağıdaki gibidir:

$C D=\sqrt{\frac{2 T}{N(N-1)}} \sum_{i=1}^{N-1} \sum_{j=i+1}^{N} \hat{\rho}_{i j}$

$\mathrm{CD}$ test, yatay kesitlerin kalıntıları arasındaki ilişki katsayılarının toplamını ifade etmektedir. Sifir hipotezi yatay kesitler arasında ilişkinin olmadığını göstermekte ve standart normal dağılmaktadır (Pesaran, 2004:9).

Dördüncü ve son test sapması düzeltilmiş $L M_{a d j}$ (BiasAdjusted Cross Sectionally Dependence Lagrange Multiplies) testidir. $L M_{a d j}$ testi, Pesaran (2008) tarafindan geliştirilmiş bir testtir.

$L M_{a d j}=\sqrt{\frac{2}{N(N-1)}} \sum_{i=1}^{N-1} \sum_{j=i+1}^{N} T \hat{\rho}_{i j} \frac{(T-k) \hat{\rho}_{i j}^{2}}{\sqrt{v_{T i j}^{2}}}$

Bu modeldeki k regresör numarasını, $v_{T i j},(T-k) \hat{\rho}_{i j}^{2}$ 'nin ortalamasını, $v_{T i j}^{2}$ ise $(T-k) \hat{\rho}_{i j}^{2}$ 'nın varyansını ifade etmektedir. Elde edilen test istatistiği asimptotik olarak standart normal dağılmaktadır (Pesaran vd., 2008:108). 
Genel olarak bu dört test için kurulan hipotezler;

\section{$H_{0}$ : Yatay Kesit Bă̆ımlılı̆̆ Yoktur.}

\section{$H_{1}$ : Yatay Kesit Bă̆ımlılı̆̆ $\mathrm{V}$ Vardır.}

Yapılan testler sonucunda sıfır hipotezi kabul edilirse yatay kesit bağımlılı̆̆ı olmadığından birinci nesil birim kök testlerinin kullanılmalıdır. Eğer alternatif hipotez kabul edilirse ikinci nesil birim kök testi kullanılmalıdır (Baltagi, 2014: 284).

Tablo 5. Yatay Kesit Bağımlılığı Testi Sonuçları

\begin{tabular}{lcccc}
\hline Sabit & \multicolumn{2}{c}{ GSYİH } & \multicolumn{2}{c}{ AR-GE } \\
\hline & $\begin{array}{c}\text { Test } \\
\text { İstatistiği }\end{array}$ & $\begin{array}{c}\text { Olasılık } \\
\text { Değeri }\end{array}$ & $\begin{array}{c}\text { Test } \\
\text { Istatistiği }\end{array}$ & $\begin{array}{c}\text { Olasilık } \\
\text { Değeri }\end{array}$ \\
\hline $\begin{array}{l}\text { CD LM1 } \\
\text { (Breusch-Pagan, 1980) }\end{array}$ & $137.148^{* *}$ & 0.019 & $172.758^{*}$ & 0.000 \\
\hline $\begin{array}{l}\text { CD LM2 } \\
\text { (Pesaran, 2004, CDLM) }\end{array}$ & $2.218^{* *}$ & 0.013 & $4.676^{*}$ & 0.000 \\
\hline $\begin{array}{l}\text { CD LM } \\
\text { (Pesaran, 2004) }\end{array}$ & $-2.240^{* *}$ & 0.013 & $-2.939^{*}$ & 0.002 \\
\hline $\begin{array}{l}\text { LMadj } \\
\text { (Pesaran vd., 2008) }\end{array}$ & $19.047^{*}$ & 0.000 & $2.084 * *$ & 0.013 \\
\hline
\end{tabular}

Not: * ve $* *$, sirasılyla $\% 1$ ve $\% 5$ anlamlılık düzeyini ifade etmektedir

Tablo 5'de yer alan sonuçlara göre, değişkenlere ait olasılık değeri \%5'ten küçük olduğu için sifir hipotezi kabul edilmemiş ve alternatif hipotez kabul edilerek serilerde yatay kesit bağımlılığının olduğuna karar verilmiştir. Serilerde yatay kesit bağımlılığının var olması yükselen piyasa ekonomisi içinde yer alan ve çalışmamızda kullanılan ülkelerden birine gelen ekonomik büyümeye ve ar-ge giderleri şokunun diğer ülkeleri etkilediğini ifade eder. Bundan dolayı, yükselen piyasa ekonomisinde yer alan ve çalışmada kullanılan bir ülkenin ekonomik politikalar belirlenirken, diğer ülkelerin büyüme ve ar-ge harcamalarını etkileyen şoklara da bakılmalıdır. Seriler arasında yatay kesit bağımlılı̆̆1 olduğundan dolayı birim kök testinde, eşbütünleşme analizinde ve eşbütünleşme tahmincisinde yatay kesit bağımlılı̆̆ını dikkate alan panel testlerinin yapılması gerekmektedir (Nazlığlu, 2010:104). Bundan dolayı çalışmada, yatay kesit bağımlılığını dikkate alan ikinci nesil birim kök testleri ve eşbütünleşme testleri kullanılmıştır.

Çalışmada ilk olarak serilerin durağanlığını test etmek için Pesaran (2007) tarafından geliştirilen "Yatay Kesit Genelleştirilmiş Dickey Fuller (CADF)" ikinci nesil birim kök testi yapılmıştır. İkinci nesil birim kök testlerinin tercih edilmesinin en önemli neden olarak serilerde yatay kesit bağımlılı̆̆1 olması gösterilebilir. Yatay kesit bağımlılığını dikkate alan CADF testi gecikmeli yatay kesit ortalamaları ve birinci farkın varlığ 1 faktör yapısı ve birimler arası korelasyon dikkate alınmaktadır (Tatoğlu, 2012:223-224). $\mathrm{Bu}$ testin hem $\mathrm{N}>\mathrm{T}$ hem de $\mathrm{N}<\mathrm{T}$ olduğu durumlarda geçerli olmaktadır (Pesaran, 2007:269; Güloğlu ve İvrenci, 2010:383). Yapılan birim kök test sonucunda elde edilen değerler ise Pesaran'ın (2007) çalışmasındaki kritik değerler ile karşılaştırılmaktadır.

CADF testinin $\mathrm{t}$ istatistik değeri şu şekilde hesaplanmaktadır (Pesaran, 2007: 269):

$t_{i}(N, T)=\frac{\Delta \hat{Y}_{i} \overline{M_{w}} Y_{i-1}}{\widehat{\sigma}\left(\hat{Y}_{i-1} \overline{M_{W}} Y_{i-1}\right)^{1 / 2}}$
Pesaran (2007) birim kök testinde CADF sonuçları ile birlikte her bir yatay kesitin durağanlığını gösteren CIPS sonuçları yer almaktadır. CIPS istatistiği için yatay kesitlerin her biri için tek tek hesaplanan t- istatistiklerinin ortalaması alınmaktadır (Pesaran 2007:276; Nazlığlu, 2010: 92; Tatoğlu, 2012:224).

CIPS $=\frac{1}{N} \sum_{i=1}^{N} \operatorname{CADF}_{i}(N, T)$

Pesaran'ın (2007) çalışmasındaki kritik değerler dikkate alınarak paneli oluşturan her ülkenin birim kök istatistiği CADF ve panelin genelini oluşturan değişkenlerin durağanlığını test etmek için yapılan CIPS test istatistiği sonuçları Tablo 6'da özetlenmiştir.

Tablo 6. GSYIHH ve AR_GE CADF Birim Kök Testi Sonuçları

\begin{tabular}{lcccc}
\hline \multicolumn{5}{c}{ Test İstatistikleri } \\
\hline & Sabit + Trend & Sabit & Sabit + Trend & Sabit \\
\hline GSYİH & $\Delta$ GSYİH & AR-GE & $\Delta$ AR-GE \\
\hline Arjantin & -2.739 & -2.558 & 0.050 & -0.514 \\
\hline Brezilya & 0.326 & -1.193 & 0.065 & -0.140 \\
\hline Kolombiya & -1.437 & -1.631 & -2.333 & -3.232 \\
\hline Macaristan & -1.366 & -1.462 & -3.019 & $-4.447^{*}$ \\
\hline Hindistan & -2.901 & -1.517 & -3.128 & $-3.731^{* *}$ \\
\hline Letonya & -0.070 & $-16.218^{*}$ & -0.473 & -2.019 \\
\hline Malezya & -0.053 & $-3.876^{*}$ & -2.233 & $-3.574^{* * *}$ \\
\hline Meksika & -0.653 & -0.172 & -2.080 & -2.933 \\
\hline Polonya & -1.751 & $-9.482^{*}$ & 3.504 & -0.761 \\
\hline Rusya & -1.234 & -1.879 & -2.202 & $-5.798^{*}$ \\
\hline G. Afrika & -2.145 & -1.805 & -1.445 & -2.707 \\
\hline Tayland & -3.613 & -2.611 & -0.521 & -1.761 \\
\hline Türkiye & -3.689 & -0.322 & -1.563 & -1.970 \\
\hline Ukranya & -3.999 & -2.503 & 0.638 & 0.189 \\
\hline Panel (CIPS) & -1.438 & $-3.288^{*}$ & -1.202 & $-2.525^{*}$ \\
\hline Not* & &
\end{tabular}

Not: *, ** ve *** sirasiyla $\% 1, \% 5, \% 10$ anlamlılık düzeyini ifade etmektedir. Panelin geneli ve ülkeler için kritik değer Pesaran (2007) çalışmasından alınmıştır. Ülkeler için sabit ve trendli modelde kritik değerler -4.98(\%1), -3.99 (\%5), -3.54 (\%10) alınmıştır. Panelin geneli için bakılan CIPS kritik değeri 2.47(\%1), 2.28(\%5), 2.14(\%10) alınmıştır (Pesaran, 2007:275-280).

Tablo 6'daki ülkelerin GSYİH birim kök test istatistiği sonuçlarına göre düzeyde sabit ve trendli durağan olmadıkları tespit edilmiştir. Birinci farkları alındığında ise Letonya, Malezya ve Polonya'nın durağan hale geldikleri bulgulanmıştır. Ülkelerin Ar-Ge harcamaları incelendiğinde düzeyde sabit ve trendli durağan olmadığı, birinci farkları alındığında ise Kolombiya, Hindistan, Macaristan, Malezya ve Rusya'nın durağan oldukları tespit edilmiştir. Panelin geneline bakıldığında, GSYİH ve AR-GE'nin düzeyde durağan olmadığı, birinci farkları alından durağan hale geldikleri görülmüştür. Yani, GSYİH ve AR-GE serilerinin I(1) olduğuna ulaşılmıştır.

Analizde kullanılan seriler arasında yatay kesit bağımlılığının olması ve serilerin homojen olması yapılacak en uygun eş bütünleşme testinin Westerlund (2008) DurbinHausman (Durbin-H) yöntemi olduğunu ortaya çıkarmıştır.

Westerlund (2008) tarafından geliştirilen Durbin-H eş bütünleşme testi ile ekonomik büyüme ile ar-ge harcamaları arasındaki eş bütünleşme ilişkisi analiz edilmiştir. Westerlund (2008) Durbin-H eş bütünleşme testi serilerin homojen ve yatay kesit bağımlılığının olduğu durumlarda uzun dönemli ilişkisi test etmek için kullanılmaktadır. Ayrıca, bu testin uygulanabilmesi için serilerin I(1) olması 
gerekmektedir. Durbin-H eș bütünleșme testi panel modeli aşağıdaki gibi hesaplanmaktadır (Westelund, 2008: 199).

$y_{i t}=\alpha_{i}+\beta_{i} x_{i t}+z_{i t}$

$x_{i t}=\delta_{i} x_{i t-1}+w_{i t}$

Model 11'daki $z_{i t}$ dağılımı ortak faktörlerin kullanımını sağlamaktadır. Durbin-H eş bütünleşme testinde yatay kesit bağımlılığına izin veren denklem seti ile ortak faktörün uyumlu olduğu varsayılmaktadır (Westerlund, 2008: 199).

$z_{i t}=\lambda_{i}^{\prime} F_{t}+e_{i t}$,

$F_{j t}=\rho_{j} F_{j t-1}+u_{j t}$,

$e_{i t}=\Phi_{i} e_{i t-1}+u_{i t}$,

Her j için $p_{i t}<1$.

$F_{t}, F_{j t}(\mathrm{j}=1, \ldots, \mathrm{k})$ ile $\mathrm{k}$ boyutlu ortak faktör vektörüdür. $\lambda_{i}$ ise faktör yüklerinin uyumlu vektörüdür (Westerlund, 2008:199).

Durbin-H testini oluşturmak için ise ilk olarak 11 denklemin farkı alınmaktadır (Westerlund, 2008:201).

$\Delta z_{i t}=\lambda_{i}^{\prime} \Delta F_{t}+\Delta e_{i t}$

16. modelde $\Delta z_{i t}$ bilinmiyorsa temel bileşenler analizinin uygulanması gerekmektedir (Westerlund, 2008:201).

$\Delta \hat{z}_{i t}=\Delta y_{i t}-\hat{\beta}_{i} \Delta x_{i t}$

Durbin-H testi kendi için de grup ve panel olmak üzere iki istatistik barındırmaktadır. Panel ve grup test istatistikleri aşağıdaki gibi modellenmektedir (Westerlund, 2008:203):

$D H_{g}=\sum_{i=1}^{n} \hat{S}_{i}\left(\widetilde{\Phi}_{i}-\widehat{\Phi}_{i}\right)^{2} \sum_{t=2}^{T} \hat{e}_{i t-1}^{2}$

$D H_{p}=\hat{S}_{n}\left(\widetilde{\Phi}_{i}-\widehat{\Phi}_{i}\right)^{2} \sum_{i=1}^{n} \quad \sum_{t=2}^{T} \hat{e}_{i t-1}^{2}$

Model 18'daki Durbin-H grup istatistiği otoregresif parametrenin heterojen olduğunu varsaymaktadır. Model 19'da panel istatistiği ise otoregresif parametrelerin homojen olduğunu varsaymaktadır (Westerlund, 2008:203). Bu iki test için kurulan eş bütünleşme hipotezi ise şu şekildedir:

\section{$H_{0}$ : Bütün birimler İçin Eş Bütünleşme Yoktur.}

$H_{1}$ : Bazı Birimler İçin Eş Bütünleşme Vardır.

Durbin-H eş bütünleşme test istatistiğinde sıfır hipotezinin reddedilmesi durumu tüm panel için eş bütünleşme ilişkisinin olduğunu göstermektedir (Westerlund, 2008:203).

Seriler arasında uzun dönemde eş bütünleşme ilişkinin varlığı test etmek için yapılan Westerlund (2008) Durbin-H. panel eş bütünleşme testi sonuçları Tablo 7'de açıklanmıştır.

Tablo 7. Durbin-H Eş bütünleşme Testi Sonuçları

\begin{tabular}{ccc}
\hline $\begin{array}{c}\text { Model } \\
\text { GSYİH=f(Ar-Ge) }\end{array}$ & Test İstatistiği & Olasılık Değeri \\
\hline $\begin{array}{c}\text { Durbin-H Grup } \\
\text { İstatistiği } \\
\text { Durbin-H Panel } \\
\text { İstatistiği }\end{array}$ & $58.724 *$ & 0.000 \\
\hline
\end{tabular}

Not: *, \%1'de istatistiksel olarak anlamlılığ ifade etmektedir.

Tablo 7'de yükselen piyasa ekonomisindeki ülkelerin panel eş bütünleşme ilişkileri verilmiştir. Durbin-H grup ve Durbin-H panel istatistiklerinde eş bütünleşme ilişkisinin olmadığı yönündeki sıfır hipotezi reddedilmektedir. Diğer bir ifadeyle, modeldeki seriler arasında eş bütünleşme ilişkisinin var olduğuna karar verilmiştir.

Durbin-H eş bütünleşme testi ile seriler arasında uzun dönemde ilişkinin olduğu belirlendikten sonra Ar-Ge ve GSYİH arasındaki nedensellik ilişkisi test etmek için Dumitrescu ve Hurlin (2012) tarafından geliştirilen nedensellik testi ile sınanmıştır.

Serilerin yatay kesit bağımlılığını ve homojenliğini dikkate alan panel nedensellik testi olan Dumitrescu ve Hurlin (2012), $\mathrm{T}>\mathrm{N}$ ve $\mathrm{N}>\mathrm{T}$ olduğu durumlarda kullanılabilmekte ve dengesiz panel verilerde etkin sonuçlar ortaya koymaktadır (Dumitrescu ve Hurlin, 2012:1457). Dumitrescu ve Hurlin (2012) nedensellik testi, Granger nedensellik testi ile benzerlik göstermektedir. Ayrıca, eşbütünleşme ilişkisinin varlığı veya yokluğu durumunda etkn sonuçlar vermektedir. Whnc, Zhnc ve Ztild'den oluşan üç farklı test istatistiği hesaplanmaktadır. Bu test istatistikleri aşağıdaki gibi gösterilmektedir (Dumetriscu ve Hurlin, 2012:1-5).

$W_{N, T}^{H n c}=\frac{1}{N} \sum_{i=1}^{N} W_{i, T}$

$Z_{N, T}^{H n c}=\sqrt{\frac{N}{2 K}}\left(W_{N, T}^{H n c}-K\right) \frac{d}{N, T \rightarrow \infty} N(0,1)$

$Z_{N}^{H n c}=\frac{\sqrt{N}\left[-N^{-1} \sum_{i=1}^{N} E\left(W_{i, T}\right)\right]}{\sqrt{N^{-1} \sum_{i=1}^{N} \operatorname{Var}\left(W_{i, T}\right)}} \frac{d}{N \rightarrow \infty} N(0,1)$

Dumitrescu ve Hurlin (2012) test istatistiklerinden Zhnc $\left(Z_{N, T}^{H n c}\right) \mathrm{T}>\mathrm{N}$ olmas1 durumunda kullanılan ve asimtotik dağılıma sahip olan bir testtir. Yarı asimtotik dağılıma sahip olan Ztild $\left(Z_{N}^{H n c}\right)$ test istatistiği ise $\mathrm{T}<\mathrm{N}$ olduğu durumlarda kullanılmaktadır. Dumetriscu ve Hurlin (2012) testinin hipotezleri ise aşağıdaki gibidir (Göçer, 2013:230):

$H_{0}: \beta_{i}^{(k)}=0 \forall i$ için, tüm yatay kesitlerde $\mathrm{X}$ 'ten $\mathrm{Y}$ 'ye nedensellik ilişkisi yoktur.

$H_{1}: \beta_{i}^{(k)}=0 \forall i=1,2, \ldots, N_{1}$ için ve,

$H_{1}: \beta_{i}^{(k)} \neq 0 \forall i=N_{1}+1 N_{1}+2, \ldots, N$ için

bazı yatay kesitlerde $X$ 'ten $Y^{\prime}$ 'ye nedensellik ilişkisi vardır.

Dumitrescu ve Hurlin (2012) tarafindan geliştirilen nedensellik testi sonuçları Tablo 8'da özetlenmiştir.

Tablo 8. Dumitrescu ve Hurlin Nedensellik Sonuçları

\begin{tabular}{|c|c|c|c|c|}
\hline & \multicolumn{2}{|c|}{$\begin{array}{l}\text { Ar-Ge, GSYİH'nin Nedensel } \\
\text { Değildir }\end{array}$} & \multicolumn{2}{|c|}{$\begin{array}{l}\text { GSYİH, Ar-Ge'nin } \\
\text { Nedenseli Değildir }\end{array}$} \\
\hline & $Z_{N, T}^{H n c}$ & $Z_{N}^{H n c}$ & $Z_{N, T}^{H n c}$ & $Z_{N}^{H n c}$ \\
\hline Model & $\begin{array}{c}2.6141 * * \\
(0.016)\end{array}$ & $\begin{array}{c}2.4536^{* *} \\
(0.041)\end{array}$ & $\begin{array}{l}6.3953^{*} \\
(0.000)\end{array}$ & $\begin{array}{l}8.5628 * \\
(0.000)\end{array}$ \\
\hline
\end{tabular}
göstermektedir.

Yükselen piyasa ekonomisinde 15 ülkenin olması ve bu ülkelerin zaman boyutunun 20 olarak alındığından yani zaman boyutu yatay kesit boyutundan büyük olduğundan dolayı asimptotik dağılım sonuçlarına dayalı olan $Z_{N, T}^{H n c}$ test istatistiği yorumlanmıştır. Dumitrescu ve Hurlin'in (2012) $Z_{N, T}^{H n c}$ panel test istatistiği sonuçlarına göre seriler arasında çift yönlü bir nedensellik ilişkisi vardır. Bu sonuç, Ar-Ge harcamalarındaki herhangi bir artışın ekonomik büyümeyi etkilediğini, ekonomik büyümedeki bir artışında Ar-Ge 
harcamalarını etkilediğini ifade etmektedir. Panel nedensellik testi sonuçlarında değişkenler arasında çift yönlü bir nedensellik ilişkisinin var olduğu tespit edilmiştir. Ayrıca, Dumitrescu ve Hurlin nedensellik sonucu kurulan sıfir hipotezlerinin reddedildiğini göstermektedir. Bu sonuç, ampirik literatürdeki Gülmez ve Yardımcıŏlu (2012), Göçer (2013), Altıntaş ve Mercan (2015) tarafindan desteklenmektedir.

\section{Sonuç ve Değerlendirme}

$\mathrm{Bu}$ çalışmada, yükselen piyasa ekonomisinde yer alan 15 ülkenin 1996-2015 yılları arasındaki ar-ge kapsamında yapılan harcamaları ile ekonomik büyüme arasında uzun dönemli bir ilişkinin var olup olmadığ arasındaki nedensellik ilişkisinin yönü panel veri analizi ile test edilmiştir.

Panel veri analizinde öncelikle paneli oluşturan verilerin yatay kesit bağımlılığı varlığı, Breusch ve Pagan (1980), Pesaran (2004) ve Pesaran vd. (2008) testleri ile incelenmiştir. $\mathrm{Bu}$ testler sonucunda yükselen piyasa ekonomisinde yer alan ülkelerin Ar-Ge harcamaları ve ekonomi büyüme değişkenlerinde yatay kesit bağımlılığı olduğuna karar verilmiştir. Serilerde yatay kesit bağımlılığının olması, ülkelerden birinde ortaya çıkan ekonomik bir şokun diğer ülkelerde de bir şok etkisi ortaya çıkartacağını ifade etmektedir. Bundan dolayı, yükselen piyasa ekonomisindeki bir ülke ekonomik politikalarına karar verirken, diğer ülkelerin ekonomik göstergelerini göz önünde bulundurması gerekmektedir.

Değişkenlerin durağanlığını test etmek için yatay kesit bağımlılığını dikkate alan Pesaran (2007) CIPS testi yapılmış ve serilerin farkta durağan olduğu görülmüştür. Serilerin birinci farkta durağan olması, yükselen piyasa ekonomisindeki ülkelerde ortaya çıkan ekonomik şokun kısa süreli olmadığını göstermektedir.

Çalışmada serilerin farkta durağan olması eşbütünleşme ilişkisinin varlığını gösterdiğinden eş bütünleşme katsayılarının homojenliği Pesaran ve Yamagata (2008) tarafından geliştirilen Delta Homojenlik testi ile sınanmıştır. Delta testi sonucunda modeli oluşturan katsayıların homojen olduğu bulgusuna ulaşılmıştır.

Eş bütünleşme ilişkisi ise yatay kesit bağımlılığını ve homojenliğini dikkate alan Westerlund (2008) Durbin-H eş bütünleşme testi ile sınanmıştır. Yapılan Durbin-H eş bütünleşme testi sonucunda Ar-Ge harcamaları ile ekonomik büyüme arasında uzun dönemde bir eş bütünleşme ilişkisinin olduğu tespit edilmiştir.

Ar-Ge ile ekonomik büyüme arasındaki nedensellik ilişkisi ise Durbin-Hurlin (2012) ile test edilmiş ve Ar-Ge harcamaları ile ekonomik büyüme arasında çift yönlü bir nedensellik ilişkisinin olduğu bulgusuna ulaşılmıştır.

Sonuç olarak, yükselen piyasa ekonomilerinde Ar-ge harcamalarının ekonomik büyümeyi olumlu yönde etkilediği ve aralarında karşılıklı bir ilişkinin olduğu tespit edilmiştir. $\mathrm{Bu}$ sonuç, sürdürülebilir bir büyüme için yükselen piyasa ekonomisindeki ülkelerin Ar-Ge yatırımlarına daha fazla kaynak ayırması gerekmektedir. Yükselen piyasa ekonomileri enflasyonist baskılar, faiz oranlar1, kur dalgalanmaları ve sosyo-politik belirsizlikler gibi birçok riski bünyesinde barındırmakla birlikte dünya ortalamasından daha yüksek büyüme oranlarına sahiptir.

Yükselen piyasa ekonomisi ülkelerinde, daha fazla sermayenin daha fazla kazanç firsatı sunmasına yönelik çalışmaların yapılarak dış yatırımların ülkeye çekilmesi büyük önem arz etmektedir. Bu kapsamda gerekli ekonomik büyümenin gerçekleştirilerek gelişmiş ekonomiler arasına girilmesi, bünyesinde bulundurdukları sosyo-politik risklerden kurtulması ve bunların gerçekleştirilebilmesinde gereken sermayenin ülkeye çekilebilmesi için Ar-Ge yatırımlarına ayrılan kaynakların artırılması büyük öneme sahiptir.

\section{Kaynakça}

Aghion, P., \& Howitt, P. (1992). A Model of Growth Through Creative Destruction. Econometrica, 60(2), 323-351.

Akıncı, M., \& Sevinç, H. (2013). Ar-Ge Harcamaları ile Ekonomik Büyüme Arasındaki İlişki: 1990-2011 Türkiye Örneği. Uluslararası Sosyal Araştırmalar Dergisi, 6(27), 7-17.

Altın, O., \& Kaya, A. A. (2009). Türkiye'de Ar-Ge Harcamaları ve Ekonomik Büyüme Arasındaki Nedensellik İlişkinin Analizi. Ege Akademik Bakış, 9(1), 251-259.

Altıntaş, H., \& Mercan, M. (2015). Ar-Ge Harcamaları ve Ekonomik Büyüme İlişkisi: OECD Ülkeleri Üzerine Yatay Kesit Bağımlılığı Altında Panel Eşbütünleşme Analizi. Ankara Üniversitesi SBF Dergisi, 70(2), 345376.

Audretsch, D. B., \& Feldman, M. P. (1996). R\&D Spillovers And The Geography Of İnnovation And Production. American Economic Review, 86, 630-640.

Baltagi, B. H. (2013). Econometric Analysis of Panel Data. Fifth Edition, Wiley.

Barro, R. J. (1990). Government Spending in a Simple Model of Endogenous Growth. Journal of Political Economy, 98(5), 103-125.

Bassanini, A., \& Scarpetta, S. (2001). The Dricing Forces of Economic Growth: Panel Data Evidence For The OECD Countries. OECD Economic Studies, No:33.

Bor, Y. J., Chuang, Y., Lai, W., \& Yang, C. (2010). A Dynamic General Equilibrium Model for Public R\&D Investment in Taiwan. Economic Modelling, 27(1), 171183

Bozkurt, C. (2015). R\&D Expenditures and Economic Growtj Relationship in Turkey. International Journal of Economics and Financial Issues, 5(1), 188-198.

Breusch, T. S., \& Pagan, A. R. (1980). The Lagrange Multiplier Test and Its Application to Model Specifications in Ecocometrics. Review of Economic Studies, 47, 239-25.

Chang, Y. (2004). Bootstrap Unit Root Tests in Panels with Cross-sectional Dependency. Journal of Econometrics, 120, 263-293. 
Coe, D. T., \& Helpman, E. (1995). International R\&D Spillovers. European Economic Review, 39 (5), 859-887.

Dominique, G., \& Pottelsberghe de la Potterie, B. (2001). R\&D and Productivity Growth: Panel Data Analysis of 16 OECD Countries. OECD Science, Technology and Industry Working Papers, 2001/3, OECD Publishing.

Dosi, G. (1988). Sources, Procedures and Microeconomic Effects of Innovestion. Journal of Economie Literature, 26, 1120-1171.

Dumitrescu, E. I., \& Hurlin, C. (2012). Testing for Granger Non-Causality in Heterogeneous Panels. Economic Modelling, 29(4), 1450-1460.

Genç, M. C., \& Atasoy, Y. (2010). Ar-Ge Harcamaları ve Ekonomik Büyüme İlişkisi: Panel Veri Analizi. Bilgi Ekonomisi ve Yönetimi Dergisi, 5(2), 27-34.

Goel, R. K., \& James, E. P., \& Ram, R. (2008). R\&D Expenditures and U.S. Economic Growth: A Disaggregated Approach. Journal of Policy Modeling, 30(2), 237-250.

Göçer, İ. (2013). Ar-Ge Harcamalarının Yüksek Teknolojili Ürün İhracat1, Dış ticaret Dengesi ve Ekonomik Büyüme Üzerindeki Etkileri. Maliye Dergisi, 165, 165-240.

Grossman, G. M., \& Helpman, E. (1991). Innovation and Growth in the Global Economy. MIT Press, Cambridge, Mass.

Gülmez, A., \& Yardımcıŏ̆lu, F. (2012). OECD Ülkelerinde Ar-Ge Harcamaları ve Ekonomik Büyüme İlişkisi: Panel Eşbütünleşme ve Panel Nedensellik Analizi (19902010). Maliye Dergisi, 163, ss:335-353.

Güloğlu, B., \& Tekin, R. B. (2012). A Panel Causality Analysis of Relationship Among Research and Development, Innovation and Economic Growth in highIncome OECD Countries. Eurasian Economic Review, 2(1), 32-27.

Gümüş, E., \& Celikay, F. (2015). R\&D Expenditure and Economic Growth: New Empirical Evidence. The Journal of Applied Economic Research, 9(3), 205-217.

IMF, (2017). International Monetary Fund, World Economic Outlook. (Accessed on 03.03.2018), http://www.imf.org/external/pubs/ft/weo/2017/02/weod ata/index.aspx

Korkmaz, S. (2010). Türkiye'de Ar-Ge Yatırımları ve Ekonomik Büyüme Arasındaki İlişkinin VAR Modeli ile Analizi. Journal of Yaşar Univesity, 20(5), 3320-3330.

Lichtenberg, F. R. (1992). R\&D Investment and International Productivity Differences. NBER Working Paper Series, No:4161, 1-39.

Lucas, R. E. (1988). On The Mechanics Of Economic Development. Journal of Monetary Economics, NorthHolland, 22, 3-42.

Melemen, M. (2007). Çin: Uluslararası Ticarette Yükselen Pazar Ekonomisi. Türkmen Kitabevi, İstanbul.

Miller, R. R. (1998). Selling to Newly Emerging Markets. Greenwood Publishing Group.
Nazlıŏlu, S. (2010). Makro Iktisat Politikalarının Tarım Sektörü Üzerindeki Etkileri: Gelişmiş ve Gelişmekte Olan Ülkeler İçin bir Karşılaştırma. Doktora Tezi. Kayseri: Erciyes Üniversitesi.

OECD (1993). The Measurement of Scientific and Technological Activities: Standard Practice for Surveys of Research and Experimental Development. (Accessed on 07.03.2018), https://www.oecdilibrary.org/docserver/9789264063525-en.pdf

Omoregia, U. (2015). A Developing Country's Absorprite Capacity: The Ling Between FDI and Economic Growth in Nigeria. Open Access Library Journal, 2, 1-7.

Osorio, B. B., \& Pose, A. R. (2004). From R\&D to Innovation and Economic Growth in the EU. Growth and Change, 35(4), 434-455.

Özcan, B., \& Arı, A. (2014). Araştırma-Geliştirme Harcamaları ve Ekonomik Büyüme İlişkisi: Panel Veri Analizi. Maliye Dergisi, 16, 39-55.

Pesaran, H. M. (2004). General Diagnostic Tests for Cross Section Dependence in Panels. University of Cambridge Working Paper, No: 0435.

Pesaran, H. M., \& Yamagata, T. (2008). Testing Slope Homogeneity in Large Panels. Journal of Econometrics, 142, 50-93.

Pesaran, M. H. (2006). Estimation and Inference in Large Heterogeneous Panels with a Multifactor Error Structure, Econometrica, 74(4), 967-1012.

Pesaran, H. M. (2007). A Simple Panel UnitRoot Test in the Presence of Cross Section Dependence. Journal of Applied Econometrics, 22(2), 265-312.

Romer, P. M. (1990). Endogenous Technological Change. Journal of Political Economy, 98, 71-102.

Romer, P. M. (1986). Increasing Returns and Long-Run Growth. The Journal of Political Economy, 94 (5), 10021037

Sadraoui, T., Ali, T. B., \& Deguachi, B. (2014). Economic Growth and International R\&D Cooperation: A Panel Granger Causality Analysis. International Journal of Econometrics and Financial Management, 2(1), 7-21.

Sağlam, Y., Egeli, H. A., \& Egeli, P. (2017). Gelişmiş ve Gelişmekte Olan Ülkelerde Ar\&Ge Harcamaları ve Ekonomik Büyüme Arasındaki İlişki: Panel Veri Analizi. Sosyoekonomi Dergisi, 25(31), 149-165.

Samimi, A. J., \& Alerasoul, S. M. (2009). R\&D and Economic Growth: New Evidence From Some Developing Countries. Australian Journal of Basic and Applied Sciences, 3(4), 3464-3469.

Serén, F., \& Jesus, M. (1999). Aggregate R\&D Expenditure and Endogenous Economic Growth. (Accessed on 16.04.2018), http://pareto.uab.es/wp/1999/43699.pdf

Trajtenberg, M. (1990). Economic analysis of product innovation: The case of CT scanners (Vol. 160). Harvard University Press.

Ülkü, H. (2004). R\&D, Innovation and Economic Growth: An Empirical Analysis. IMF Working Paper. 
WP/04/185. (Accessed on 15.03.2018), http://www.imf.org/ /media/Websites/IMF/importedfull-text-pdf/external/pubs/ft/wp/2004/_wp04185.ashx

Westerlund, J. (2007). Testing for Error Correction in Panel Data. Oxford Bulletin of Economics and Statistics, 69(6), 709-748.

Westerlund, J. (2008). Panel Cointegration Tests of the Fisher Effect. Journal of Applied Econometrics, 23, 193233.

Yanyun, Z., \& Mingqian, Z. (2004). R\& D and Economic Growth: Panel Data Analysis in ASEAN+3 Countries. In: A Joint Conference of AKES, RCIE, and KDI: Korea and the World Economy, III, July 3-4, Sungkyunkwan University, Seoul, Korea. (Accessed on 15.03.2018), https://faculty.washington.edu/karyiu/confer/seoul04/pa pers/zhao.pdf

Yu-Ming, W., Li, Z., \& Jian-Xia, L. (2007). Co-integration and Causality Between R\&D Expenditure and Economic Growth in China:1953-2004. International Conference on Public Administration, 76, 869-876. 
